\title{
Synthesis, Spectroscopy and X-ray Crystallography Structure of Pyridine 4-Carbaldehyde Semicarbazone Schiff Base Ligand
}

\author{
Farzaneh Mahmoudi $^{a, *}$, Saeed Farhadi ${ }^{a, *}$, Michal Dusek ${ }^{\text {b }}$, Morgane Poupon ${ }^{\text {b }}$ \\ a Department of Chemistry, Lorestan University, Khoramabad 68151-44316, Iran \\ b Institute of Physics of the Czech Academy of Sciences, Na Slovance 2, 18221 Prague 8, Czech Republic
}

\begin{tabular}{|c|c|}
\hline ART I C L E I N F O & A B S T R A C T \\
\hline Received: 09 November 2019 & In this work, pyridine 4-carbaldehye semicarbazone Schiff base ligand (HL) \\
\hline Revised: 16 December 2019 & was synthesized with condention of pyridine 4-carbaldehyde and \\
\hline Accepted: 05 January 2020 & semicarbazide hydrochloride in reflux method. The HL was characterized \\
\hline Available online: 22 January 2020 & $\begin{array}{l}\text { using the CHN elemental analysis, FT-IR, UV-Vis, and }{ }^{1} \mathrm{H} \text { NMR spectroscopy. } \\
\text { The single crystals of HL prepared and used for the X-ray crystallography. } \\
\text { Single-crystal X-ray diffraction revealed that, HL crystallized in a triclinic }\end{array}$ \\
\hline K E Y W O R D S & system with the space group P-1. The FT-IR spectra and X-ray \\
\hline
\end{tabular}

Schiff base ligand

Crystal structure

Spectroscopy

G R A P H I C A L A B S T RA C T

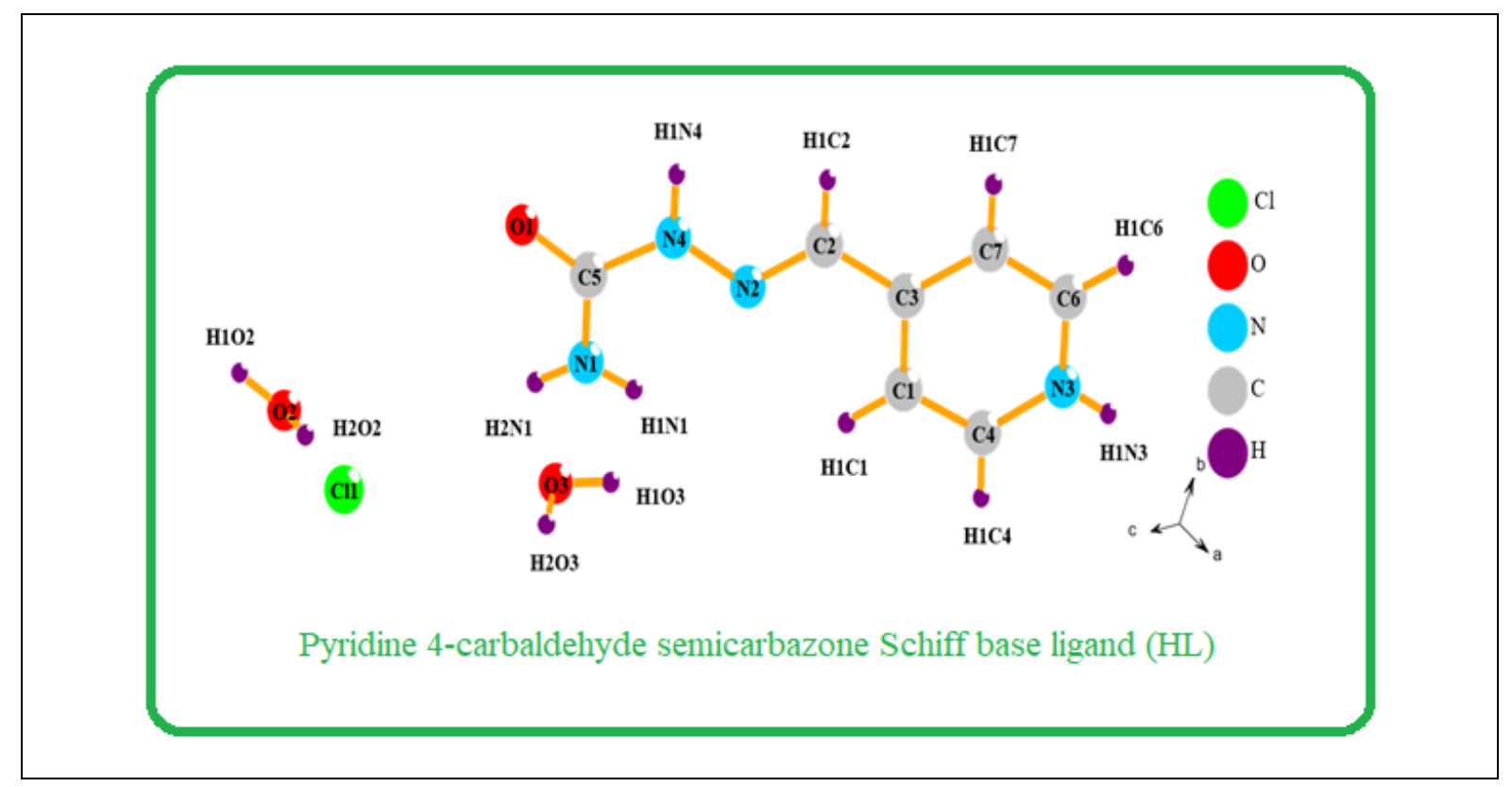

* Corresponding author's E-mail address: farzanehmahmoudi@yahoo.com (F. Mahmoudi), sfarhadi1348@yahoo.com (S.Farhadi) 


\section{Introduction}

Schiff bases are known as imines or azomethines and are used as ligands for synthesis of complexes using different metal ions. They are obtained from condensation reaction of primary amines and aldehydes or ketones. Often, aldehydes react faster and better than ketones because of the steric and electronic effects [1-3]. For many years, they have been introduced as chelating ligands in transition metal coordination chemistry, because of easy synthesis routes, extensive availability and versatility of structure related to their potential applications in catalysis, analytical, pharmacological, and magnetism [4-5]. Schiff bases are also used as significant intermediates for synthesis of various bioactive materials [69]. Countless Schiff bases and their coordination complexes with outstaning antimicrobial activity, antifungal, and anticancer abilities have been reported [8-13]. The Schiff bases with pyridine ring have received more attention in literature [14-15]. The semicarbazones and thiosemicarbazones usually behave as chelating ligands, which are versatile in both neutral and anionic forms [16-18]. Metal complexes of semicarbazones and thiosemicarbazones have gained special attention due to their importance in medicine and biological system [19-20]. Furthermore, the metal complexes of semicarbazones have demonstrated antimicrobial [21,22], anticancer [23], and antiviral activities [24,25]. The first report for synthesis of pyridine 2-carbaldehyde semicarbazone ligand dates in 1955 [26,27], discovering its antifungal activity. Keeping on that, we reported several transition metal compounds based on this ligand [25, 28-30]. Herein we synthesized a new semicarbazone ligand by the reaction of semicarbazide hydrochloride and pyridine 4-carbaldehyde under reflux conditions and characterized it with several analyses. Furthermore the structure of the HL was determined using the Xray crystallography and discussed completely.

\section{Experimental}

Generel

The chemicals and solvents contains pyridine 4-carbaldehye, semicarbazide hydrochloride and ethanol were purchased from Merck. Fourier-transform infrared spectra were recorded on Shimadzu FT-IR 8400 S (Japan) using $\mathrm{KBr}$ pellet. Microanalyses were carried out using a Heraeus CHN-O- Rapid analyzer. The uncorrected melting point was measured on an Electrothermal 9100 apparatus. ${ }^{1} \mathrm{H}$ NMR spectra were recorded on a Bruker AVANCE 300-MHz instruments at room temperature with the signal of the free deuterated methanol, $\mathrm{CD}_{3} \mathrm{OD}$ solvent using TMS as internal reference. UV-Vis spectrum was recorded on a Carry 100 Conc Varian spectrophotometer.

Synthesis of pyridine 4-carbaldehyde semicarbazone (HL)

At first, semicarbazide hydrochloride (10 mmol, $1.1 \mathrm{~g}$ ) was added to $40 \mathrm{~mL}$ ethanol in a round bottom flask and heated at $75{ }^{\circ} \mathrm{C}$. It refluxed for $2 \mathrm{~h}$ at this temperature till dissolved completely in ethanol. Then pyridine 4carbaldehyde (10 mmol, $1 \mathrm{~mL}$ ) was dissolved in $10 \mathrm{~mL}$ ethanol and was added dropwise to the above solution under refux condition. The mixture was refluxed on water bath for $6 \mathrm{~h}$ at 75 ${ }^{\circ} \mathrm{C}$ and the precipitate of HL was formed. After cooling the solution to room temperature, the precipitate was collected, washed with ethanol, dried in air and used without further purification. Yield: $1.8 \mathrm{~g}$ (83\%), [m.p. $153{ }^{\circ} \mathrm{C}$ ]. For synthesis of single crystals of HL with slow evaporation method, after collecting the precipitate, the solution of reaction was kept at room temperature. After 5 days, the white crystals of HL were formed at vessel of reaction. The crystals were collected and dried at room temperature. Anal. Calcd for $\mathrm{C}_{7} \mathrm{H}_{13} \mathrm{ClN}_{4} \mathrm{O}_{3}$ : C, 35.5; H, 5.65; N, 23.67. Found: C, 35.7; H, 5.52; N, 23.80. Characteristic FT-IR data $\left(\mathrm{KBr}, \mathrm{cm}^{-1}\right)$ : 
$3386 \mathrm{~m}, v\left(-\mathrm{NH}_{2}\right) ; 3220 \mathrm{~m}, v(\mathrm{~N}-\mathrm{H}) ; 1704 \mathrm{~s}, \quad v(\mathrm{C}=\mathrm{O}) ; 1604 \mathrm{~s}, v(\mathrm{C}=\mathrm{N}) ; 1087 \mathrm{~s}, v(\mathrm{~N}-\mathrm{N})$.

Scheme 1. Synthesis of pyridine 4-carbaldehyde semicarbazone Schiff base ligand (HL)

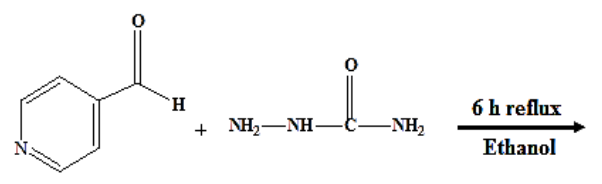<smiles></smiles>

Table 1. Crystal and structure refinement data for $\mathrm{HL}$

\begin{tabular}{|c|c|}
\hline Chemical Formula & C7H13CIN4O3 \\
\hline Formula weight & 236.66 \\
\hline Crystal description & Plate, transparent \\
\hline Crystal size $(\mathrm{mm})$ & $0.13 \times 0.13 \times 0.04$ \\
\hline Temperature (K) & 95 \\
\hline Crystal system & triclinic \\
\hline Space group & $P-1$ \\
\hline$a(\AA)$ & $4.6415(1)$ \\
\hline$b(\AA)$ & $8.8704(3)$ \\
\hline$c(\AA)$ & $14.1176(5)$ \\
\hline$\alpha\left(^{\circ}\right)$ & $104.918(3)$ \\
\hline$\left.\beta 0^{\circ}\right)$ & $95.654(3)$ \\
\hline$\gamma\left(\left(^{\circ}\right)\right.$ & $100.799(3)$ \\
\hline Volume $\left(\AA^{3}\right)$ & $545.08(3)$ \\
\hline$Z$ & 2 \\
\hline$\rho$ calculated $\left(\mathrm{g} / \mathrm{cm}^{-3}\right)$ & 1.442 \\
\hline$\mu\left(\mathrm{mm}^{-1}\right)$ & 3.112 \\
\hline Largest diff. peak and hole $\left(\mathrm{e}^{-}{ }^{-3}\right)$ & $0.28-0.31$ \\
\hline Final R indices $[\mathrm{I}>3 \sigma(\mathrm{I})]$ & $0.0352(2033)$ \\
\hline Final $\mathrm{R}$ indices (all data) & $0.0953(2194)$ \\
\hline
\end{tabular}

\section{Crystallographic analysis}

The single crystal X-ray diffraction experiments were performed using a Super Nova four circles diffractometer equipped with an Atlas S2 detector and an micro focus source $\left(\mathrm{Cu}-\mathrm{K}_{\alpha, \text { average }}=1.54184 \AA\right)$. The data were collected at $95 \mathrm{~K}$ on a single crystal of suitable size $\left(0.13 \times 0.13 \times 0.04 \mathrm{~mm}^{3}\right)$, using $\omega$ scans and detector-sample distance $53 \mathrm{~mm}$. The diffracted intensities were collected up to $75.420^{\circ}(-5 \leq h$ $\leq 5 ;-11 \leq k \leq 10$ and $-17 \leq l \leq 16$ ). The experimental details are summarized in Table 1.

The structure has a triclinic unit cell with $a=$ $4.6415 \AA, b=8.8704 \AA, c=14.1176 \AA$. $\alpha=$ $104.918^{\circ}, \beta=95.654^{\circ}$ and $\gamma=100.799^{\circ}$. The data reduction and absorption correction were done by the software Crys Alis Pro [31], merging of symmetry equivalent reflections yielded $R_{\text {int }}=$ 0.056 . The structure was solved by charge flipping (Super flip [32]) for space group $P-1$. The refinement was performed with the software Jana 2006. The anisotropic displacement parameters (ADP) were used for $\mathrm{N}, \mathrm{C}, \mathrm{O}$ and $\mathrm{Cl}$. The hydrogens atoms were inserted are insert by symmetry and positions were refined for nitrogen and oxygen atoms. The hydrogen ADP are restrained for 1.2 times $\mathrm{U}_{\text {eq. }}$. The final merit factor are $R_{o b s}=3.52 \%$ and $\mathrm{wR}_{\mathrm{all}}=9.53 \%$.

\section{Results and discussions}

Most of the semicarbazone ligands display keto-enol tautomerism in coordination to metal ion centers as neutral or deprotonated ligands [16-20]. Preparation of the pyridine 4carbaldehyde semicarbazone ligand (HL) was revealed by infrared spectroscopy (Figure 1). The FT-IR spectrum of HL revealed a strong 
band at $1704 \mathrm{~cm}^{-1}$ and two medium bands at 3386 and $3220 \mathrm{~cm}^{-1}$ for $\mathrm{C}=\mathrm{O},-\mathrm{NH}_{2}$ and $\mathrm{N}-\mathrm{H}$ stretching, and a sharp band at 1087 related to $\mathrm{N}-\mathrm{N}$ bond. Observation of sharp band corresponding to $\mathrm{C}=\mathrm{O}$ bond, suggests the keto form for HL and interestingly presence of a strong band at $1604 \mathrm{~cm}^{-1}$ reveals the imine functionality in HL. The bands at 2754 and 2986 $\mathrm{cm}^{-1}$ correspond to $\mathrm{C}-\mathrm{H}$ bond of aldehyde. The strong bands at $1419 \mathrm{~cm}^{-1}$ and $1450-1580 \mathrm{~cm}^{-1}$ are related to aliphatic $\mathrm{C}-\mathrm{N}$ bonds and aromatic $\mathrm{C}=\mathrm{C}$ bonds, respectively. The low energy inplane and out of plane vibrations of pyridine ring are observed at 655 and $451 \mathrm{~cm}^{-1}$ respectively. Interestingly observation of bands at 3429 and $1640 \mathrm{~cm}^{-1}$ corresponding to stretching and bending vibrations of water, confirms presence of lattice water molecules in structure of HL.

The ${ }^{1} \mathrm{H}$ NMR spectrum of $\mathrm{HL}$ is demonstrated in Figure 2. The singlet resonances are observed at $\delta=10.413,10.391$ and $9.963 \mathrm{ppm}$, which are assigned to semicarbazide $\mathrm{NH} \quad\left({ }^{3} \mathrm{NH}\right)$, hydrogenated pyridine nitrogen $\left({ }^{1} \mathrm{NH}\right)$ and aldehyde $\mathrm{CH}$ groups $\left({ }^{6} \mathrm{CH}\right)$, respectively.

Figure 1. FT-IR spectrum of HL



Figure 2. ${ }^{1} \mathrm{H}$ NMR spectrum of $\mathrm{HL}$ in $\mathrm{CD}_{3} \mathrm{OD}$




The broad small peaks at the range of 9.2-9.4 ppm are related to $\mathrm{NH}_{2}$ group of semicarbazone $\left({ }^{4} \mathrm{NH}_{2}\right)$. The observed peaks at $\delta=9.985$ and $9.631 \mathrm{ppm}$ belong to the pyridine protons. The peaks at $6.524 \mathrm{ppm}$ can assigned to water molecules in structure of $\mathrm{HL}$ and the peaks at 4.929 and $4.933 \mathrm{ppm}$ are related to use $\mathrm{CD}_{3} \mathrm{OD}$ solvent for analysis.

Electronical spectra of the HL measured in methanol solvent (Figure 3). Observation of absorption bands at 224 and $328 \mathrm{~nm}$ corresponding to intra-ligand $\pi \rightarrow \pi^{*}$ transitions of the pyridin ring and imine group confirms successful synthesis of HL [28-30].

Structure of the HL is depicted in Figure 4. It crystallizes in a triclinic system, with the space group of $P-1$. X-ray crystal analysis revealed that, the structure of the HL contained a Schiff base molecule, two water molecules, and one anionic chlorine atom. The structural formula of the $\mathrm{HL}$ can be summarized as $\left[\mathrm{H}_{2} \mathrm{~L}\right]+\mathrm{Cl} \cdot\left(\mathrm{H}_{2} \mathrm{O}\right)_{2}$. According to the FI-IR data, the $\mathrm{HL}$ is not deprotonated and it is in inert form of ligand. In fact, the HL by keeping its hydrogen atom located on N3 atom exists in keto form. Moreover, the nitrogen of the pyridine ring is protonated, giving the ligand a positive charge, and a chlorine atom is located in the structure as a counter-ion. The observed chlorine atom in the structure of HL is from the semicarbazide hydrochloride, which used for synthesis of HL.

The shortest bond distances of the pyridine ring are 1.347 and $1.339 \AA$ for N3-C4 and N3$\mathrm{C} 6$ respectively. The $\mathrm{C}-\mathrm{C}$ or $\mathrm{C}=\mathrm{C}$ distances of pyridine ring are between $1.375 \AA$ and $1.400 \AA$. The selected bond distances and angles of HL are summarized at Table 2 . The $\mathrm{C}=\mathrm{N}$ bond length of HL is $1.285 \AA$ which is in good consistent with the $\mathrm{C}=\mathrm{N}$ bond distances in similar ligands [20-29]. Although the HL contains an aromatic cycle, there is no $\pi-\pi$ stacking interaction in its structure. Presence of two water molecules and chlorine ion in structure of HL plays an important role in hydrogen bond interactions, expanding the structure in three dimensions. Table 3 provides more details on the hydrogen bonding interactions in HL. Figure 5a illustrates the available individual hydrogen bonds in the structure of HL. The $\mathrm{N}_{4}-\mathrm{H}_{1} \mathrm{~N}_{4} \cdots 01$ and $\mathrm{O}_{3}-$ $\mathrm{H}_{1} \mathrm{O}_{3} \cdots \mathrm{O}_{1}$ hydrogen bonds connect molecules into layers (Figure 5b), and the layers are interconnected by hydrogen bonds of the water molecules and chloride ions.

Figure 3. UV-Vis spectra of HL

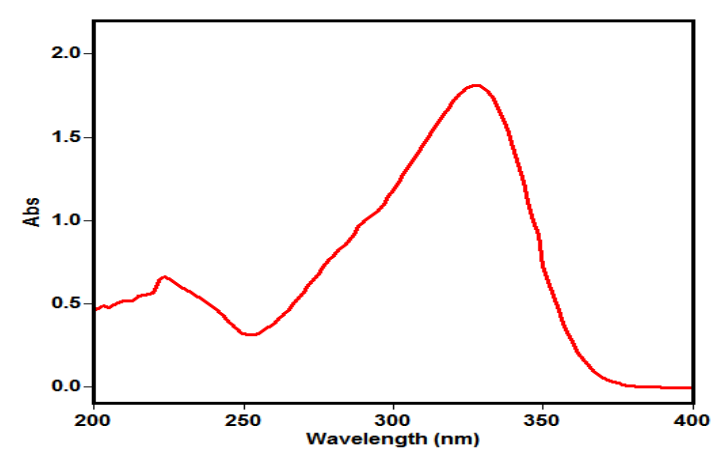

Figure

4.

Crystal

structure of HL

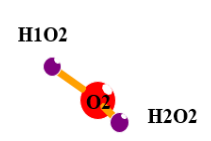

(CI1)

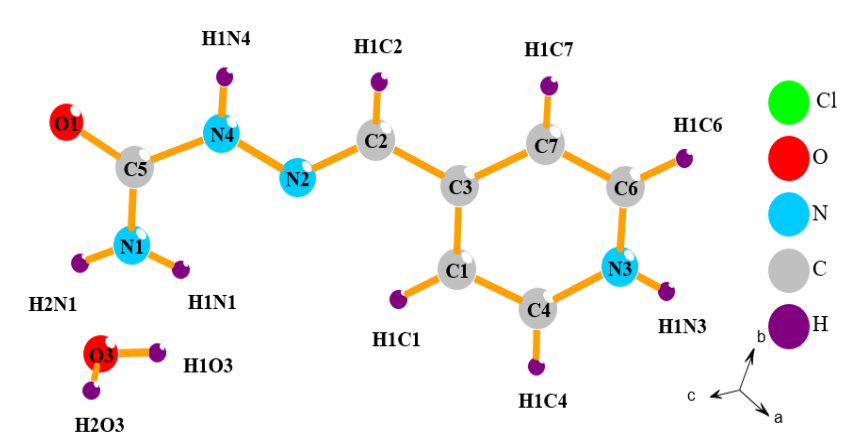


Figure 5. (a) View of hydrogen bonding interactions in $\mathrm{HL}$, (b) Expansion of $\mathrm{HL}$ with intermolecular interactions in three dimentions (green)

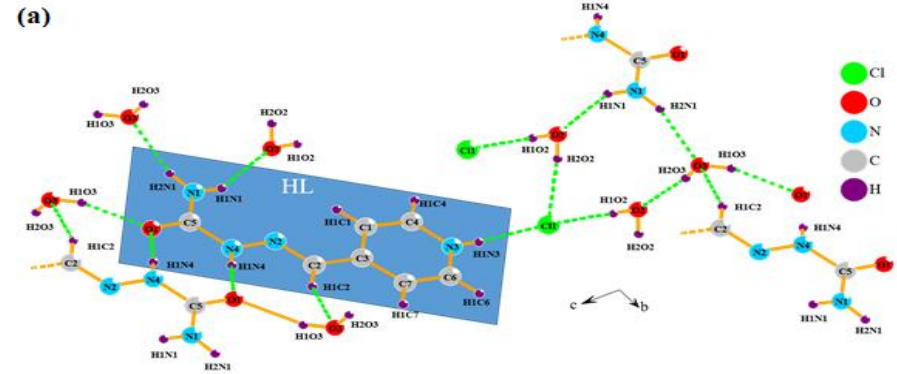

(b)

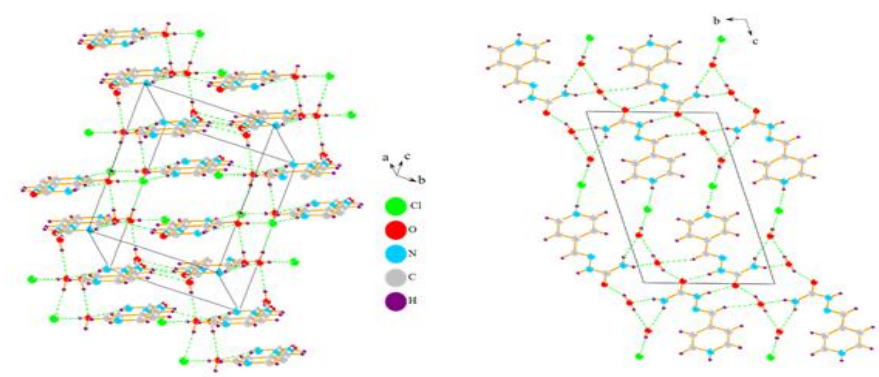

Table 2. Selected Bond Distances $(\AA)$ and Angles $\left({ }^{\circ}\right)$ of HL

\begin{tabular}{|c|c|c|c|c|c|c|c|}
\hline Atom 1 & Atom 2 & \multicolumn{2}{|c|}{ distance $(\AA)$} & Atom 1 & \multicolumn{2}{|c|}{ Atom 2} & distance $(\AA)$ \\
\hline C5 & 01 & \multirow{2}{*}{\multicolumn{2}{|c|}{$\begin{array}{l}1.2450(18) \\
1.3259(18)\end{array}$}} & N4 & \multicolumn{2}{|c|}{ C5 } & $1.3833(19)$ \\
\hline & N1 & & & & \multicolumn{2}{|c|}{ H1N4 } & 0.87 (2) \\
\hline 02 & H102 & \multicolumn{2}{|c|}{$0.85(2)$} & C1 & \multicolumn{2}{|c|}{ C3 } & $1.4002(19)$ \\
\hline & $\mathrm{H} 2 \mathrm{O} 2$ & \multicolumn{2}{|c|}{$0.87(2)$} & & \multicolumn{2}{|c|}{ C4 } & $1.375(2)$ \\
\hline 03 & H103 & \multicolumn{2}{|c|}{$0.83(3)$} & & \multicolumn{2}{|c|}{ H1C1 } & 0.96 \\
\hline & $\mathrm{H} 203$ & \multicolumn{2}{|c|}{0.75 (2) } & $\mathrm{C} 2$ & \multicolumn{2}{|c|}{ C3 } & $1.463(2)$ \\
\hline N1 & H1N1 & \multicolumn{2}{|c|}{0.84 (2) } & & \multicolumn{2}{|c|}{$\mathrm{H} 1 \mathrm{C} 2$} & 0.96 \\
\hline & $\mathrm{H} 2 \mathrm{~N} 1$ & \multicolumn{2}{|c|}{$0.84(2)$} & C3 & \multicolumn{2}{|c|}{ C7 } & $1.397(2)$ \\
\hline $\mathrm{N} 2$ & N4 & \multicolumn{2}{|c|}{1.3527 (18) } & C4 & \multicolumn{2}{|c|}{ H1C4 } & 0.96 \\
\hline & $\mathrm{C} 2$ & \multirow{2}{*}{\multicolumn{2}{|c|}{$\begin{array}{c}1.2846(19) \\
1.347(2)\end{array}$}} & C6 & \multicolumn{2}{|c|}{ C7 } & $1.380(2)$ \\
\hline N3 & C4 & & & & \multicolumn{2}{|c|}{ H1C6 } & 0.96 \\
\hline & C6 & \multicolumn{2}{|c|}{1.3391 (19) } & C7 & \multicolumn{2}{|c|}{ H1C7 } & 0.96 \\
\hline & H1N3 & \multicolumn{2}{|c|}{$0.82(2)$} & $\mathrm{Cl} 1$ & \multicolumn{2}{|c|}{ N3 } & $3.0579(14)$ \\
\hline Atom 1 & Atom 2 & Atom 3 & Angle $\left(^{\circ}\right)$ & Atom 1 & Atom 2 & Atom 3 & Angle $\left(^{\circ}\right)$ \\
\hline H102 & 02 & H2O2 & $100(2)$ & $\mathrm{N} 2$ & $\mathrm{C} 2$ & C3 & $118.40(12)$ \\
\hline H103 & 03 & H2O3 & $110(2)$ & N2 & $\mathrm{C} 2$ & $\mathrm{H} 1 \mathrm{C} 2$ & 120.8 \\
\hline C5 & N1 & H1N1 & $119.4(14)$ & C3 & $\mathrm{C} 2$ & $\mathrm{H} 1 \mathrm{C} 2$ & 120.8 \\
\hline C5 & N1 & H2N1 & 119.3 (15) & C1 & C3 & $\mathrm{C} 2$ & $121.85(13)$ \\
\hline $\mathrm{H} 1 \mathrm{~N} 1$ & N1 & H2N1 & 120.3 (19) & C1 & C3 & C7 & 118.95 (13) \\
\hline N4 & N2 & $\mathrm{C} 2$ & 116.77 (11) & $\mathrm{C} 2$ & C3 & C7 & $119.20(12)$ \\
\hline $\mathrm{Cl} 1$ & N3 & C4 & $113.31(9)$ & N3 & $\mathrm{C} 4$ & C1 & $120.04(13)$ \\
\hline $\mathrm{Cl} 1$ & N3 & C6 & $124.17(10)$ & N3 & $\mathrm{C} 4$ & $\mathrm{H} 1 \mathrm{C} 4$ & 119.98 \\
\hline $\mathrm{Cl} 1$ & N3 & H1N3 & $4.4(14)$ & C1 & $\mathrm{C} 4$ & H1C4 & 119.98 \\
\hline $\mathrm{C} 4$ & N3 & C6 & $122.50(14)$ & 01 & C5 & N1 & $124.89(14)$ \\
\hline C4 & N3 & H1N3 & 117.7 (14) & 01 & $\mathrm{C} 5$ & N4 & $117.78(12)$ \\
\hline C6 & N3 & H1N3 & 119.7 (14) & N1 & C5 & N4 & $117.33(13)$ \\
\hline $\mathrm{N} 2$ & N4 & C5 & $119.41(11)$ & N3 & C6 & $\mathrm{C} 7$ & $119.76(14)$ \\
\hline $\mathrm{N} 2$ & N4 & H1N4 & 121.5 (14) & N3 & C6 & H1C6 & 120.12 \\
\hline C5 & N4 & H1N4 & $117.7(14)$ & C7 & C6 & H1C6 & 120.12 \\
\hline C3 & C1 & $\mathrm{C} 4$ & $119.23(14)$ & C3 & C7 & $\mathrm{C} 6$ & $119.52(13)$ \\
\hline C3 & C1 & $\mathrm{H} 1 \mathrm{C} 1$ & 120.38 & C3 & C7 & $\mathrm{H} 1 \mathrm{C} 7$ & 120.24 \\
\hline
\end{tabular}

Symmetry codes: (i) $\mathrm{x}-1, \mathrm{y}, \mathrm{z}+1$; (ii) $\mathrm{x}+1, \mathrm{y}, \mathrm{z}-1$ 
Table 3. Selected hydrogen bonding parameters in HL ( $\mathrm{D}=$ donor, $\mathrm{H}=$ hydrogen and $\mathrm{A}=$ acceptor $)$

\begin{tabular}{|c|c|c|c|c|}
\hline D-H.A & $\mathrm{D}(\mathrm{D}-\mathrm{H})(\AA)$ & D (H.A) $(\AA)$ & D (D.A) $(\AA)$ & $(\mathrm{D}-\mathrm{H} \cdot \mathrm{A})\left(^{\circ}\right)$ \\
\hline $\mathrm{C} 2-\mathrm{H} 1 \mathrm{C} 2 \cdots 03^{\mathrm{iii}}$ & 0.96 & 2.49 & 3.4013 (18) & 158.72 \\
\hline $\mathrm{N} 1-\mathrm{H} 1 \mathrm{~N} 1 \cdots \mathrm{O} 2^{\mathrm{iv}}$ & $0.84(2)$ & $2.26(2)$ & 3.0087 (18) & $149.6(17)$ \\
\hline $\mathrm{N} 1-\mathrm{H} 2 \mathrm{~N} 1 \cdots 03^{\text {iv }}$ & $0.84(2)$ & $2.04(2)$ & $2.8602(16)$ & 163.7 (19) \\
\hline $\mathrm{N} 4-\mathrm{H} 1 \mathrm{~N} 4 \cdots 01^{\mathrm{v}}$ & $0.87(2)$ & $1.97(2)$ & $2.8370(16)$ & $174.2(18)$ \\
\hline $03-\mathrm{H} 103 \cdots 01^{\text {vi }}$ & $0.83(3)$ & $1.98(2)$ & 2.7833 (17) & $160.7(18)$ \\
\hline $03-\mathrm{H} 2 \mathrm{O} 3 \cdots 02^{\text {vi }}$ & $0.75(2)$ & $2.11(3)$ & 2.8555 (18) & $173(2)$ \\
\hline $\mathrm{O} 2-\mathrm{H} 102 \cdots \mathrm{Cl} 1$ vii & $0.85(2)$ & $2.28(2)$ & 3.1281 (12) & $177(2)$ \\
\hline $\mathrm{O} 2-\mathrm{H} 2 \mathrm{O} 2 \cdots \mathrm{Cl} 1$ & $0.87(2)$ & $2.28(2)$ & 3.1418 (11) & $173(2)$ \\
\hline
\end{tabular}

Symmetry codes: (ii) $\mathrm{x}+1, \mathrm{y}, \mathrm{z}-1$; (iii) $-\mathrm{x}+2,-\mathrm{y}+1,-\mathrm{z}$; (iv) $-\mathrm{x}+1,-\mathrm{y},-\mathrm{z}$; (v) $-\mathrm{x}+1,-\mathrm{y}+1,-\mathrm{z}$; (vi) $\mathrm{x}+1$, $\mathrm{y}, \mathrm{z}$; (vii) $\mathrm{x}-1, \mathrm{y}, \mathrm{z}$.

\section{Conclusion}

In this research study, a Schiff base ligand named pyridine 4-carbaldehye semicarbazone (HL) was synthesized and fully characterized. The results of the CHN elemental analysis, FT-IR, UV-Vis and ${ }^{1} \mathrm{H}$ NMR spectroscopies confirmed the successful synthesis of the HL. The X-ray crystallography of single crystals of $\mathrm{HL}$ revealed its structural formula as $\left[\mathrm{H}_{2} \mathrm{~L}\right]^{+} \mathrm{Cl}-\left(\mathrm{H}_{2} \mathrm{O}\right)_{2}$. Presence of several hydrogen bonding interaction in structure of HL expanded its structure in three dimensions. Also it was fund that, the HL can be utilized as an interesting tridendate NNO donor ligand for synthesis of novel complexes with different metal ions.

\section{Appendix A. supplementary data}

CCDC 1494841 contains the supplementary crystallographic data for the structure reported in this paper. These data can be obtained free of charge via http://www.ccdc.cam.ac.uk/conts/retrieving. $\mathrm{html}$, or from the Cambridge Crystallographic Data Centre, 12 Union Road, Cambridge CB2 1EZ, UK; fax: (+44) 1223-336-033; or e-mail: deposit@ccdc.cam.ac.uk.

\section{Acknowledgment}

The authors would like to acknowledge Lorestan University for supporting this work. The crystallographic part was supported by the project 18-10504S of the Czech Science
Foundation using instruments of the ASTRA lab established within the Operation program Prague Competitiveness-project CZ.2.16/3.1.00/24510.

\section{Disclosure statement}

No potential conflict of interest was reported by the authors.

\section{References}

[1] A.L. Berhanu, I. Mohiuddin, A.K. Malik, J.S. Aulakh, V. Kumar, K.H. Kim, Trend. Analyt. Chem., 2019, 116, 74-91.

[2] B. Bansod, T. Kumar, R. Thakur, S. Rana, I. Singh, Biosens. Bioelectron., 2017, 94, 443-455.

[3] X. Liu, J.R. Hamon, Coord. Chem. Rev., 2019, 389, 94-118.

[4] B. Shaabani, A.A. Khandar, F. Mahmoudi, S.S. Balula, L. Cunha-Silva, J. Mol. Struct., 2013, 1045, 55-61.

[5] B. Shaabani, A.A. Khandar, M. Dusek, M. Pojarova, F. Mahmoudi, Inorg. Chim. Acta, 2013, 394, 563-568.

[6] Y. Echegoyen, I. Suelves, M.J. Lazaro, M.L. Sanjuan, R. Moliner, Appl. Cat. A, 2007, 333, 229-237.

[7] S. Nayak, P. Gamez, B. Kozlevcar, A. Pevec, O. Roubeau, S. Dehnen, J. Reedijk, Polyhedron, 2010, 29, 2291-2296.

[8] S. Uddin, S. Hossain , A. Latif, R. karim, R.K. Mohapatra, K.E. Zahan, Am. J. Heterocycl. Chem., 2019, 5, 27-36. 
[9] R.M. Mannar, A. Shalu, B. Cerstin, E. Martin, R. Dieter, Dalton Trans., 2005, 537-544.

[10] C. An, X. Feng, N. Zhao, P. Liu, T. Wang, Z. Lian, J. Coord. Chem., 2014, 67, 36213632.

[11] S. Banerjee, M. Nandy, S. Sen, S. Mandal, G.M. Rosair, A.M.Z. Slawin, C.J. GómezGarcía, J.M. Clemente-Juan, E. Zangrando, N. Guidolin, S. Mitra, Dalton Trans., 2011, 40, 1652-1661.

[12] S. Chandra, S. Raizada, R. Verma, J. Chem. Pharm. Res., 2012, 4, 1612-1618.

[13] K. Dhahagani, M.P. Kesavan, G.G. VinothKumar, L. Ravi, G. Rajagopal, J. Rajesh, Mater. Sci. Eng. C, 2018, 90, 119130.

[14] M. Asadi, S. Torabi, K. Mohammadi, Spectrochim. Acta Part A., 2014, 122, 676681.

[15] J. Ortega-Castro, M. Adrover, J. Frau, A. Salva, J. Donoso, F. Munoz, J. Phys. Chem. A, 2010, 114, 4634-4640.

[16] A. Ray, S. Banerjee, R.J. Butcher, C. Desplanches, S. Mitra, Polyhedron, 2008, 27, 2409-2415.

[17] S. Farhadi, M.M. Amini, M. Dusek, M. Kucerakova, F. Mahmoudi, J. Mol. Struct., 2017, 1130, 592-602.

[18] S. Farhadi, F. Mahmoudi, M. Dusek, V. Eigner, M. Kucerakova, Polyhedron, 2017, 122, 247-256.

[19] D. Kovala-Demertzi, P. Nath Yadav, J. Wiecek, S. Skoulika, T. Varadinova, M.A. Demertzis, J. Inorg. Biochem., 2006, 100, 1558-1567.

[20] R.J. Kunnath, M. Sithambaresan, A. Ambili Aravindakshan, A. Natarajan, M.R.
Prathapachandra Kurup, polyhedron, 2016, 113, 73-80.

[21] P. Anitha, N. Chitrapriya, Y.J. Jang, P. Viswanathamurthi, J. Photochem. Photobiol. A, 2013, 129, 17-26.

[22] N.C. Kasuga, K. Onodera, S. Nakano, K. Hayashi, K. Nomiya, J. Inorg. Biochem., 2006, 100, 1176-1186.

[23] J. Benitez, L. Becco, I. Correia, S. Milena Leal, H. Guiset, J. Costa Pessoa, J. Lorenzo, S. Tanco, P. Escobar, V. Moreno, B. Garat, D. Gambino, J. Inorg. Biochem., 2011, 105, 303-312.

[24] H. Elo, Z. Naturforsch. C., 2007, 62, 498506.

[25] B. Shaabani, A.A. Khandar, F. Mahmoudi, M.A. Maestro, S.S. Balula, L.C. Silva, Polyhedron, 2013, 57, 118-126.

[26] S. Sugasawa, K. Mizukami, Pharm. Bull., 1955, 3, 393-393.

[27] E.G. Novikov, A.G. Pozdeeva, L.D. Stonov, L.A. Bakumenko, Khim. Selsk. Khoz., 1966, 4, 435-437.

[28] B. Shaabani, A.A. Khandar, M. Dusek, M. Pojarova, F. Mahmoudi, A. Feher, M. Kajňaková, J. Coord. Chem., 2013, 66, 748762.

[29] B. Shaabani, A.A. Khandar, M. Dusek, M. Pojarova, M.A. Maestro, R. Mukherjee, F. Mahmoudi, J. Coord. Chem., 2014, 67, 2096-2109.

[30] S. Farhadi, F. Mahmoudi, J. Simpson, J. Mol. Struct., 2016, 1108, 583-589.

[31] Oxford Diffraction LTd. CrysAlis CCD; Oxford Diffraction: Abington, England, 2006.

[32] L. Palatinus, G. Chapuis, J. Appl. Cryst., 2007, 40, 786-790.

How to cite this manuscript: Farzaneh Mahmoudi, Saeed Farhadi, Michal Dusek, Morgane Poupon, Synthesis, Spectroscopy and X-ray Crystallography Structure of Pyridine 4Carbaldehyde Semicarbazone Schiff Base Ligand, Adv. J. Chem. A, 2020, 3(4), 534-541.

Copyright (C) 2020 by SPC (Sami Publishing Company)+ is an open access article distributed under the Creative Commons Attribution License, which permits unrestricted use, distribution, and reproduction in any medium, provided the original work is properly cited. 